\title{
VOGAIS MÉDIAS PRETÔNICAS NO PORTUGUÊS FALADO EM CAMETÁ: ANÁLISE ACÚSTICA
}

\author{
PRETONIC MIDDLE VOWELS IN THE PORTUGUESE \\ SPOKEN IN CAMETÁ ACOUSTIC ANALIZY
}

Raquel Maria da Silva Costa Furtado ${ }^{1}$

http://lattes.cnpq.br/6834320910469690

https://orcid.org/0000-0001-6351-6192

\author{
Benedita Maria do Socorro Campos de Sousa ${ }^{2}$ \\ http://lattes.cnpq.br/2941296390551969 \\ https://orcid.org/0000-0002-3597-0416
}

Enviado em: 25/08/2020

Aceito em: 22/09/2020

\begin{abstract}
RESUMO: Este trabalho objetiva caracterizar acusticamente as vogais médias pretônicas orais /e/ e /o/ faladas na área rural de Cametá (PA). O corpus da pesquisa é constituído por 18 participantes-colaboradores, estratificados por sexo, faixa etária e escolaridade, os quais participaram de um teste de imagens. Os dados foram submetidos a um tratamento composto por 5 etapas: segmentação em 6 níveis no programa PRAAT (enunciado, lexical, vocábulo alvo, sílaba, fonológico e fonético); isolamento dos vocábulos alvo em arquivo individuais; organização dos dados em uma planilha Excel; tomadas de medidas acústicas; cálculos da média e desvio padrão dos valores em Hz de F1 e F2. Os resultados mostraram alto grau de variação entre as variantes: [i] e /e/ -participantes-colaboradores femininos; [u] e /o/ - velhos e jovens; e as baixas [ $[\mathrm{e}] \mathrm{e}[\mathrm{p}]$ apresentaram-se distanciadas das variantes altas e médias. Assim, os dados acústicos apontam para o processo de manutenção das vogais pretônicas.

Palavras-chave: Análise acústica. Vogais médias pretônicas. Linguagem oral.
\end{abstract}

ABSTRACT: This work aims to acoustically characterize the oral pretonic pretonic middle vowels /e/ and /o/ spoken in the rural area of Cametá (PA). The research corpus consists of eighteen informants, stratified by gender, age and schooling, which participated in an imaging test. The data were submitted to a treatment composed of 5 stages: segmentation at 6 levels in the PRAAT software (utterance, lexical, target word, syllable, phonological and phonetic); isolation of target words in individual files; organization of the data in an Excel spreadsheet; acoustic measures; calculations of the mean and standard deviation of the values in $\mathrm{Hz}$ of F1 and F2. The results presented a high degree of variation between the variants: [i] and /e/ -female informants; $[\mathrm{u}]$ and /o/ - old and young ones; the low $[\mathbf{u}]$ and $[\mathbf{u}]$ were distanced from the high and medium variants. Thus, the acoustic data points to the process of maintenance of the pretonic vowels

Keywords: Acoustic analysis. Vowels averages pretonic. Oral language

\section{Introdução}

A presente pesquisa aborda sobre a caracterização do espaço acústico das vogais médias pretônicas /e/ e /o/ no português falado na zona rural do munícipio de Cametá-PA. Ela surgiu

\footnotetext{
${ }^{1}$ Doutora em Linguística (UFC) em 'Descrição e Análise Linguística'. Professora Adjunta III da Faculdade de Linguagem da Universidade Federal do Pará/Campus Universitário do Tocantins/Cametá-Pará. E-mail: raqmaria@ufpa.br

2 Doutora em Linguística (UFC) em 'Descrição e Análise Linguística'. Professora Adjunta II da Faculdade de Linguagem da Universidade Federal do Pará/Campus Universitário do Tocantins/Cametá-Pará. E-mail: bmscampos@ufpa.br
} 
de estudos prévios de cunho sociolinguístico variacionista realizados sobre as variedades do português da Amazônia. Estes estudos apontaram para a preservação das médias pretônicas em detrimento do alteamento (RODRIGUES (2005); RODRIGUES E ARAÚJO (2007); CAMPOS (2008) e COSTA (2010).

O primeiro deles é de Rodrigues (2005) que investigou na zona urbana e rural o alteamento $/ \mathrm{o} />[\mathrm{u}]$ e $/ \mathrm{e} />$ [i] na variedade de Cametá em posição pretônica e tônica (maior ênfase), com 72 informantes, todos estratificados socialmente. De um total de 4.328 dados demonstrou menor ocorrência de alteamento das médias /e/ e /o/, 58\% dos dados, com um peso relativo de .58 .

Rodrigues e Araújo (2007) trataram especificamente das vogais médias /e/ e /o/ em posição pretônica na zona urbana e rural, num corpus de 36 informantes, estratificados socialmente em sexo, escolaridade, procedência e faixa etária. Os autores identificaram 4.539 dados, e os resultados apresentaram para as variantes: média anterior fechada /e/ percentual de $62 \%$; média anterior aberta /E/, $9 \%$; alta anterior /i/, 29\%; média posterior fechada /o/, 53\%; para a variante média posterior aberta $/ \mathrm{O} /, 7 \%$ e; para a variante alta posterior $/ \mathrm{u} / 40 \%$. Com base nos resultados há maior ocorrência de vogais médias fechadas $[\mathrm{e}, \mathrm{o}]$ em detrimento das vogais abertas $[\varepsilon, \mathrm{\jmath}]$ e das variantes altas $[i, u]$.

O terceiro desses trabalhos é o de Costa (2010) que analisou na zona urbana e rural o comportamento das vogais médias /e/ e /o/ em posição postônicas não-finais. O corpus da pesquisa é formado por uma amostra de 96 sujeitos-participantes estratificados socialmente por sexo, escolaridade, procedência e faixa etária. Costa (2010) obteve um total de 2.177 dados de vogais médias, das quais $47 \%$ de frequência era da presença do fenômeno de alteamento, peso relativo de 46 , e; $53 \%$, peso relativo de .54 foi da não aplicação da regra de alteamento.

Enfim, diante desses trabalhos, optamos em realizar uma análise acústica das vogais médias pretônicas faladas em Cametá, pois a intenção era colher dados linguísticos mais precisos, com traços físicos da fala mais acurados, para caracterizar e definir com maior precisão e agudez as vogais médias pretônicas em análise.

Para a concretização deste estudo, trabalhamos com um total de 18 (dezoito) participantescolaboradores, todos moradores da zona rural do município de Cametá/PA, distribuídos em três faixas etárias (15 a 25 anos; 26 a 45 anos e acima de 46 anos), sexo (masculino e feminino) e estratificados em escolaridade (níveis fundamental, médio e superior). A coleta dos dados deu-se por meio de um teste de imagem, no qual os participantes-colaboradores identificaram e produziram 72 vocábulos, de acordo com as vogais médias em análise.

Como hipóteses do nosso trabalho acreditamos que: 1) as vogais alteadas [i] $</ \mathrm{e} / \mathrm{e}[\mathrm{u}]<$ /o/ são mais frequentes na fala dos participantes-colaboradores mais velhos e de pouca escolaridade, com maior ênfase no sexo masculino; 2) a maior ocorrência da variação entre /e/ > [i] e /o/ $>[\mathrm{u}]$ encontra-se na terceira faixa etária, pois este é um público que, a princípio, encontra-se fora do mercado de trabalho e, por isso, aparentemente é mais desprendido das regras linguísticas mais rígidas ou de variantes de maior prestígio.

Todos os dados foram tratados e analisados por meio do programa computacional Praat, com o objetivo de verificar o processo de variação das vogais médias pretônicas e, assim, destacar a variante de maior predominância na zona rural do município de Cametá.

Portanto, para uma melhor comprensão da abordagem aqui realizada, este trabalho: descreve detalhadamente os procedimentos metodológicos adotados na pesquisa (seção 2); para em seguida apresentar os resultados da análise acústica (seção 3) das vogais médias pretônicas da variedade investigada; e, por fim, expõem-se as considerações finais e referências bibliográficas que embasaram a pesquisa. 


\section{Metodologia}

O corpus deste estudo é composto de uma amostra estratificada por $18^{3}$ (dezoito) colaboradores, todos procedentes da zona rural do município de Cametá-PA, estratificados em: sexo (masculino 09 e feminino 09); faixa etária: 06 (15 à 25 anos), 06 (26 à 45 anos) e 06 (acima de 46 anos ) e; nivel de escolaridade: (06 com nível fundamental, 06 com nível médio e 06 com nível superior.

Os eventos de fala ou ocorrências linguísticas, que constituíram o corpus para análise deste estudo, foram obtidos por meio de um teste de imagens ${ }^{4}$, que se referia à nomeação de 61 figuras que correspondiam a vocábulos com as vogais médias orais /e/ e /o/ em posição pretônica. Os vocábulos, em sua maioria, eram substantivos, haja vista a facilidade de representação por meio de gravuras desta classe de palavras.

A escolha de tais palavras levou em consideração vocábulos já encontrados, e com frequência significativa, em trabalhos de cunho variacionistas quantitativos (RODRIGUES; ARAÚJO, 2007; CAMPOS, 2008) entre outros, realizados nos eixos Belém, Cametá, Breves e Mocajuba. Então, tomando por base o resultado dessas pesquisas, decidimos aprofundar as análises de cunho quantitativo, utilizando o ponto de vista qualitativo, seguindo uma metodologia de tratamento dos dados de base acústica, conforme fez Cruz (2012).

O tratamento dos dados foi realizado por meio da segmentação realizada com o auxílio do programa computacional Praat. Concluída a segmentação, passamos à identificação das variações ocorridas nas vogais pretônicas. E para isso, contabilizamos as ocorrências das vogais médias/e/ e /o/ e suas variantes - [ع], [0], [i], [u] - obtidas no corpus. Para a análise das propriedades físicas de cada vogal, levantamos as seguintes informações: tipo de vogal qualidade: baixa/média/alta; a duração da vogal; extração das medidas de F1 (altura) e F2 (anterioridade e posterioridade) de cada vogal ${ }^{5}$ média pretônica na parte central da vogal alvo; por fim, com o auxílio do Praat, retiramos as medidas das médias e desvio padrão com os valores em Hz de F1 e F2 para verificar a relevância de tais formantes. Este levantamento foi feito isoladamente para cada locutor para que pudéssemos proceder à análise sem desvio que comprometesse o julgamento das variáveis.

$\mathrm{E}$, a fim de se comparar as médias de F1 e F2 em Hz das variáveis em análise, para se observar de forma mais minuciosa e com ancoragem na estatística, aplicamos o teste- $\mathrm{T}$, pois queríamos observar se havia diferenças entre as médias subjacentes e derivadas. Então, estratificamos a amostra em: jovem/adulto, masculino/feminino; jovem/jovem e adulto/adulto, para testar se há diferenças estatísticas ou não no nível de significância estabelecido de 0,05 entre as médias em análise.

\section{A análise dos dados}

Dos 18 (dezoito) participantes-colaboradores analisados neste trabalho, obtivemos um corpus formado por 455 dados de vogais médias anteriores ${ }^{6}$ /e/ (231 ocorrências de fala masculina e 224 ocorrências de fala feminina) e 473 vogais médias posteriores /o/ (230 ocorrências para a fala masculina e 243 para a fala feminina). Tais dados nos revelaram que as vogais médias /e/ e /o/ encontram-se em variação em posição pretônica, pois apresenta no nível acústico, 04 variantes: manutenção /e/ /o/ - r/e/polho, c/o/mer; alteamento $[\mathrm{i}] /[\mathrm{u}]-\mathrm{p}[\mathrm{u}]$ lícia, $\mathrm{p}[\mathrm{i}]$ pino; abaixamento $[\varepsilon] /[\mathrm{o}]$ - r[ $[\varepsilon]$ médio, qu[E]brado e; apagamento $[\varnothing]$ - $[\varnothing]$ stante, $[\varnothing]$ scola, como o já verificado por Cruz et al

\footnotetext{
3 Todos cametaenses, nascidos e residentes no município ou que tenham chegado ao município até os 7 anos de idade e que não tenham se deslocado da região por mais de dois anos consecutivos e possuir dentição completa.

${ }^{4}$ Ao entrevistado os pesquisadores argumentavam que se tratava de um teste de memória, parecido com os realizados em provas para a obtenção de carta de motorista, a fim de desviar sua atenção de questões linguísticas, e conseguir uma fala menos monitorada possível e a mais próxima da espontaneidade.

${ }^{5}$ Analisamos somente os dados orais, não incluímos as vogais nasalizadas e nasais.

6 Incluindo a vogal subjacente /e/ e suas derivadas [E] e [i].
} 
(2012) para o dialeto de Belém, e encontradas em análises de cunho quantitativo realizadas sobre o dialeto investigado, como em Rodrigues e Araújo (2007).

Baseando-se nisso, apresentamos os valores de Média Desvio Padrão das frequências formânticas de F1 e F2 em Hz e os números de ocorrências de cada variante, conforme referência (quadro 1).

Quadro 1: Número de ocorrências das variantes das vogais médias pretônicas, média e desvio padrão dos valores em $\mathrm{Hz}$ de F1 e F2 de cada variante analisada.

\begin{tabular}{|c|c|c|c|c|c|c|c|c|c|c|}
\hline \multirow{2}{*}{ Variantes } & \multicolumn{2}{|c|}{ N de ocorrências } & \multicolumn{4}{|c|}{ Média } & \multicolumn{4}{c|}{ Desvio Padrão } \\
\cline { 3 - 11 } & & & F1 & F1 & F2 & F2 & F1 & F2 & F1 & F2 \\
\cline { 2 - 11 } & Masc. & Fem. & Masc. & Fem. & Masc. & Fem. & Masc. & Fem. & Masc. & Fem. \\
\hline i & 35 & 42 & 378 & 425 & 2010 & 2204 & 53 & 57 & 199 & 371 \\
\hline e & 128 & 138 & 418 & 469 & 1915 & 2195 & 44 & 42 & 189 & 217 \\
\hline$\varepsilon$ & 68 & 44 & 502 & 572 & 1778 & 2099 & 51 & 45 & 173 & 161 \\
\hline $\mathrm{u}$ & 32 & 39 & 430 & 452 & 1229 & 1281 & 55 & 76 & 333 & 258 \\
\hline o & 129 & 137 & 468 & 488 & 1134 & 119 & 64 & 55 & 219 & 225 \\
\hline o & 69 & 67 & 562 & 608 & 1095 & 1194 & 87 & 73 & 231 & 125 \\
\hline
\end{tabular}

Fonte: própria dos autores.

Notamos, assim, no quadro 01, a manutenção manifestando-se como variante de maior ocorrência no português falado na zona rural do município de Cametá, tanto para a fala masculina como para a feminina - 128 e 138, respectivamente. Tais comportamentos no falar da população de Cametá/zona rural são verificados nos resultados de Cruz, Costa e Silva (2012) que identificaram um alto índice de manutenção das vogais médias pretônicas na capital paraense - Belém/PA, destacando-se as vogais médias anteriores - 138 ocorrências, contra 76 ocorrências das posteriores.

O alto índice de manutenção das vogais médias pretônicas ainda é destacado no resultado de Rodrigues e Araújo (2007) - /e/ 1.775 ocorrências, percentual de 62\% e; /o/ 891 ocorrências 53\%; e outros trabalhos na região amazônica como de: Dias et al (2007), Cassique et al (2009), Oliveira (2007), Campos (2008), Cruz et al (2008) e Sousa (2010).

Detectamos as médias baixas como variante de segunda maior ocorrência, d com ligeira preferência na fala dos homens. Este resultado destoa das análises de cunho sociolinguístico quantitativo realizadas na região do baixo Tocantins, as quais apresentam como segunda variante de maior ocorrência o alteamento (RODRIGUES, 2005; RODRIGUES e ARAÚJO, 2007). Porém, Cruz et al (2012), para o dialeto da zona urbana de Belém, equipara-se aos resultados aqui encontrados, na medida em que observa frequência de ocorrências das variantes baixas $-[\varepsilon]$ e $[0]-$ maior do que as variantes altas - [i ] e [ u ], embora este dados sejam resultantes de corpus de fala lida e não de teste de imagens.

Assim, para que tenhamos uma abordagem mais panorâmica da realização das médias pretônicas, dispusemos abaixo, o gráfico 1, a fim de compararmos os dados fonéticos desta pesquisa (análise acústica), com os dados sociolinguísticos ${ }^{7}$ (análise quantitativa) de Rodrigues (2005).

\footnotetext{
${ }^{7}$ Análises quantitativas.
} 


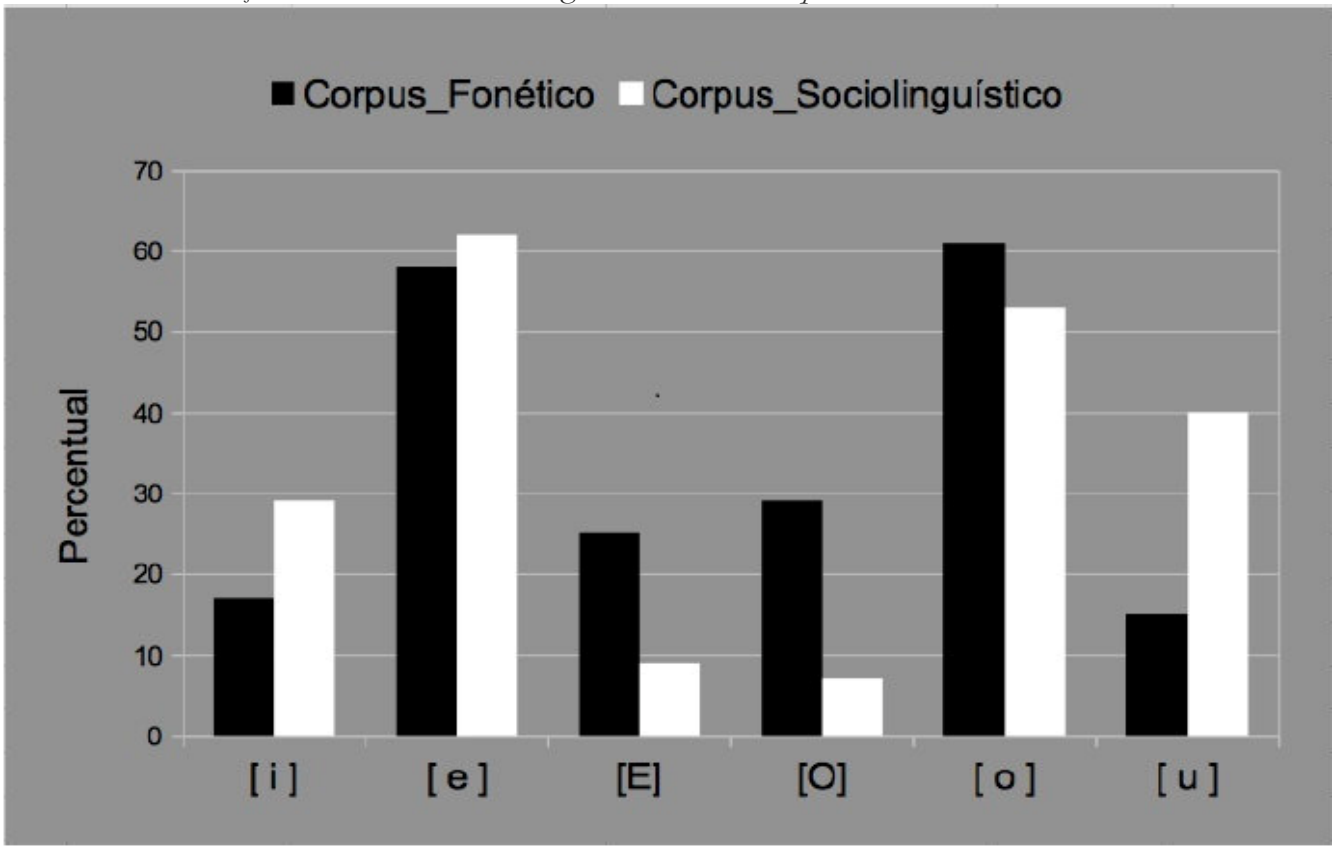

Fonte: Própria das autoras

O gráfico 01 demonstra os dados em percentual, contendo as vogais alvo - /e/ e /o/ - e suas variantes - [i], $[\mathrm{e}],[\varepsilon],[0],[\mathrm{o}],[\mathrm{u}] . \mathrm{O}$ corpus foneticamente ${ }^{8}$ controlado reitera o predomínio das variantes médias fechadas /e/ e /o/ indicado pelo corpus sociolinguístico. Por outro lado, as duas corpora destoam quanto ao ranqueamento da terceira e quarta variantes $[\varepsilon]$ e $[0]$, pois há uma diferença bastante significativa entre os dois resultados, sendo que na pesquisa de cunho quantitativo, tais variantes mostraram-se de pouca ocorrência, e na análise acústica aqui empreendida, foneticamente controlada, essas vogais baixas apresentam ocorrência superior às altas.

Partiremos daqui em diante para a caracterização das vogais médias de acordo com as variáveis sexo e faixa etária.

\subsection{Estratificação por sexo}

Os resultados apontam, para os valores retirados em $\mathrm{Hz}$ de F1 e F2, que as vogais da série anterior, por apresentarem menor grau de variação, ocupam espaço acústico bem discriminado e definido entre si, o que não ocasiona discrepância entre o posicionamento ocupado por esse grupo vocálico; com exceção da média $[\varepsilon]$, tanto da fala feminina quanto da masculina, que demonstrou maior polarização em relação ao restante do grupo. Na fala feminina, em relação ao primeiro formante F1, eixo vertical, a média $[\varepsilon]$ apresenta valor maior do que a $[\varepsilon]$ da masculina, o que a torna mais baixa ainda, gerando assim maior distanciamento acústico da vogal alta [i], conforme pode ser notado no gráfico 02 .

\footnotetext{
${ }^{8}$ Essa diferenciação entre os resultados talvez seja em decorrência do tipo de análise que se realiza, pois a análise acústica é mais acurada e proporciona um espelhamento com maior propriedade dos traços físicos e formânticos que constituem cada um desses fonemas vocálicos, o que é mais difícil ser captado por uma análise de cunho quantitativo, baseada somente na percepção auditiva.
} 
Gráfico 02: Médias de valores de Hz de F1 e F2 das três variantes das vogais médias pretônicas dos dados de fala feminina e masculina do corpus de fala de imagens da variedade de Cametá, zona rural (BE8).

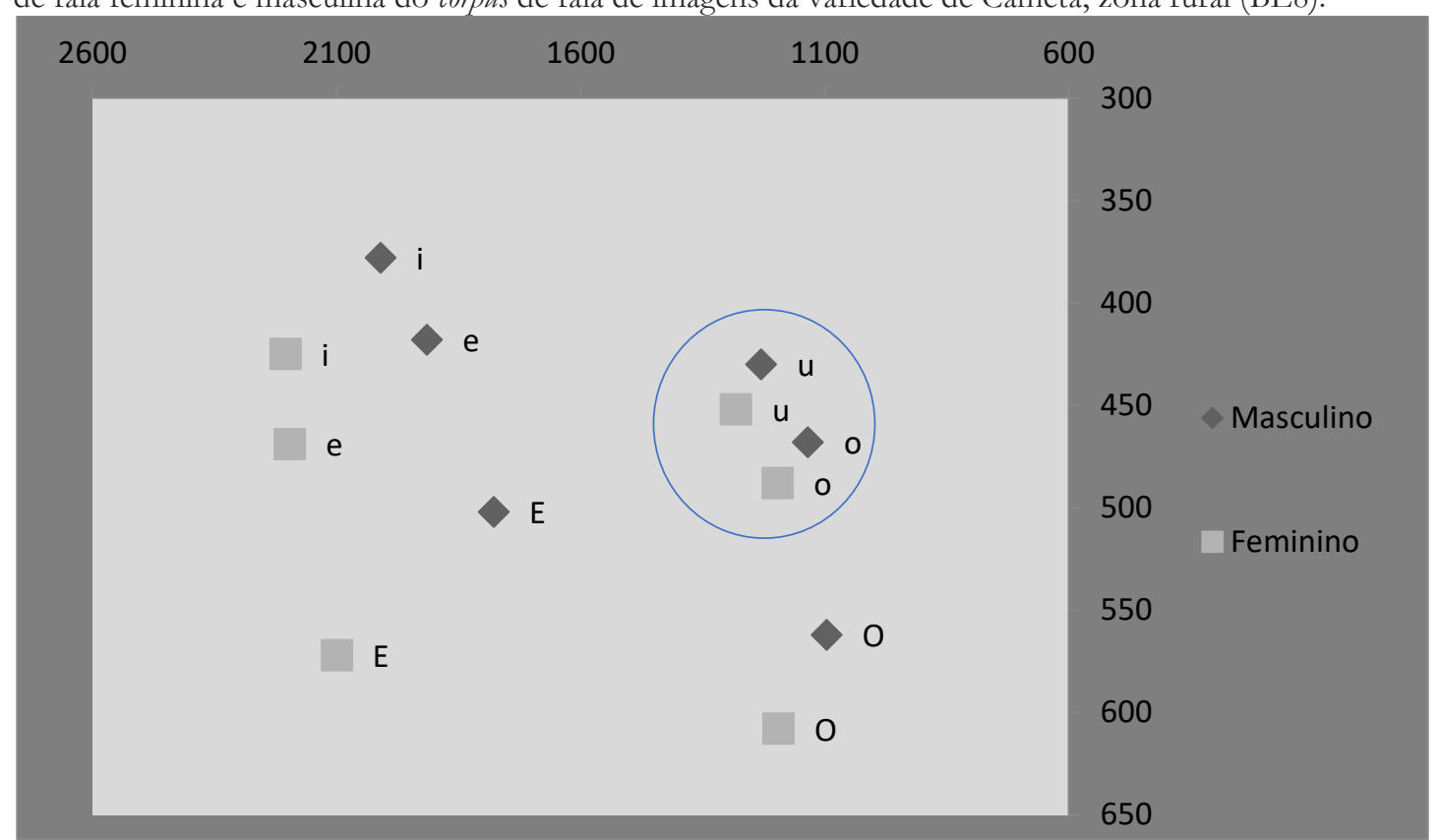

Fonte: Elaboração própria

Observa-se, ainda, na fala feminina, as vogais anteriores: a) com F1 mais elevado do que a série anterior da masculina; e b) na fala masculina F2 com tendência significativa à centralização, principalmente, a média baixa $[\varepsilon]$, que além de mais central é bem mais alta de que a média baixa feminina.

No que se refere à série posterior, verificamos a partir do espaço acústico, forte índice de variação na série posterior entre a alta $[\mathrm{u}]$ e a média alta /o/, tanto na fala feminina quanto na masculina, pois há maior aproximação fonética e menor espaço de contrastes entre ambas. Para Sândalo e Abaurre (2013) esta proximidade entre as variantes, como o observado entre /o/ e [u] acima, representa um alto grau de variação entre elas, e o maior distanciamento entre tais variantes, indica menor grau de variação, como o atestado para a série anterior. Enquanto a posterior [0] feminina têm F1 mais alta do que a masculina, o que consequentemente, torna a variante mais baixa do quadro acústico.

Diante disso, poderíamos concluir que a língua falada na zona rural de Cametá apresenta maior tendência ao processo de alteamento das posteriores /o/ e [u], do que das anteriores /e/ e [i] e isso constitui um traço típico do falar desta região, seja em posição tônica (COSTA, 2004; RODRIGUES, 2005); postônica (OLIVEIRA, 2008; COSTA, 2010) e; na pretônica (RODRIGUES e ARAÚJO, 2007; LOPES, CRUZ e COSTA, 2014; MORAES, 2015); pois há variação significativa entre /o/ e [u], muito embora essa variante não seja a mais empregada na linguagem falada de Cametá.

Portanto, temos um sistema vocálico acústico, para a série posterior, mais polarizado para o falar cametaense rural, em que as vogais médias altas fechadas e as médias abertas estão mais distantes entre si, principalmente em relação ao primeiro formante. Somente a média posterior alta fechada /o/ e a vogal alta [u] da fala masculina e feminina compartilham espaço acústico bem próximos.

Este quadro acústico das médias na fala feminina e na masculina cametaense diferencia-se dos resultados apresentados por Cruz et al (2012) para a série anterior com os dados de fala lida de Belém, pois para as autoras, a anterior alta derivada (fala masculina e feminina) ocupa quase o mesmo espaç,o acústico que a variante alta média fechada, e ambas apresentam-se distantes da variante média aberta. No que diz respeito à série posterior, os resultados aqui encontrados equi- 
param-se aos achados de Cruz et al (2012). No trabalho da autora a vogal [u], /o/ e [0] da fala masculina e feminina apresentam espaço acústico bastante próximo.

E com o intuito de testarmos estatisticamente os resultados da análise acústica, para observarmos se as variáveis diferem entre si, a partir da comparação dos valores das médias de F1 de tais variantes, aplicou-se o teste de estatística descritiva teste-T, cujo objetivo era verificarmos se há divergência ou não entre tais variantes, como na tabela 01.

Tabela 01 - Quadro com o resultado do teste-T aplicado às médias e desvio padrão das amostras de fala dos participantes-colaboradores do sexo masculino referentes aos protocolos de teste induzido por imagens.

\begin{tabular}{|c|c|c|c|c|c|}
\hline$[\mathbf{i}] \mathbf{x}[\mathbf{i}]$ & $/ \mathrm{e} / \mathbf{x} / \mathbf{e} /$ & {$[\varepsilon] \mathbf{x}[\varepsilon]$} & {$[\mathbf{u}] \mathbf{x}[\mathbf{u}]$} & $/ \mathbf{o} / \mathbf{x} / \mathbf{o} /$ & {$[\mathbf{o}] \mathbf{x}[\mathbf{p}]$} \\
$\mathbf{M}-\mathbf{F}$ & $\mathbf{M}-\mathbf{F}$ & $\mathbf{M}-\mathbf{F}$ & $\mathbf{M}-\mathbf{F}$ & $\mathbf{M}-\mathbf{F}$ & $\mathbf{M}-\mathbf{F}$ \\
\hline 0,0003 & 0,000000008 & 0,0000008 & $\mathbf{0 , 7 9 9 8}$ & $\mathbf{0 , 0 6 7 8}$ & 0,0000009 \\
\hline
\end{tabular}

Fonte: Elaboração própria

E, como notamos na tabela 01 , a diferença entre os valores estatísticos foram inferiores ao valor padrão estabelecido de significância do teste-T $<\mathbf{0 , 0 5}$, no que tange às variantes masculinas

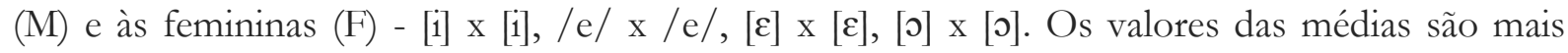
elevados, no que diz respeito às médias baixas $[\varepsilon] \times[\varepsilon] \mathrm{e}[0] \mathrm{0}[\mathrm{0}]$, pois se apresentam bem distante entrei si, o que confirma, o espaço acústico encontrado nesta pesquisa. Ao contrário de $[\mathrm{u}] \mathrm{x}[\mathrm{u}]$ e /o/ x /o/, que manifestaram valores acima do nível de significância, o que demonstra não haver diferença significativa entre os sexos na produção das vogais $[\mathrm{u}] \mathrm{e} / \mathrm{o} /$, comprovando os dados acústicos de que tais vogais encontram-se muito próximas foneticamente no diagrama acústico.

E para refinarmos mais ainda as comparações entre as variantes realizou-se um teste, tomando como categoria de análise somente a variável sexo, como visto na tabela 02 , a fim de constatarmos se existem diferenças estatisticamente significantes entre tais vogais em variação.

Tabela 02: Quadro com o resultado do teste T aplicado nas médias e desvio padrão das amostras de fala dos participantes-colaboradores do sexo masculino referentes aos protocolos de teste induzido por imagens.

\begin{tabular}{|c|c|c|c|c|c|}
\hline \multicolumn{3}{|c|}{ TESTE - T Feminino } & \multicolumn{3}{|c|}{ TESTE - T Masculino } \\
\hline [i] $\mathrm{x} / \mathrm{e} /$ & [i] $\times[\varepsilon]$ & $/ \mathrm{e} / \mathrm{x}[\varepsilon]$ & {$[\mathrm{i}] \mathrm{x} / \mathrm{e} /$} & {$[\mathrm{i}] \times[\varepsilon]$} & $/ \mathrm{e} / \mathrm{x}[\varepsilon]$ \\
\hline 0,005 & 0,000003 & 0,00001 & 0,003 & 0,000001 & 0,0000002 \\
\hline$[\mathrm{u}] \times / \mathrm{o} /$ & {$[\mathrm{u}] \times[\mathrm{y}]$} & $/ 0 / \times[0]$ & {$[\mathrm{u}] \times / \mathrm{o} /$} & {$[\mathrm{u}] \times[\mathrm{O}]$} & $/ \mathrm{o} / \mathrm{x}[\mathrm{D}]$ \\
\hline 0,003 & 0,00000001 & 0,0000003 & 0,003 & 0,00000002 & 0,0008 \\
\hline
\end{tabular}

Fonte: própria das autoras

E a estatística ratifica que as diferenças entre as vogais $[\mathrm{u}]</ \mathrm{o} /$ são relevantes, tanto da fala masculina quanto da feminina, com 0,003 de nível de significância, o que nos levar a afirmar que são vogais significativamente distintas na variedade do português em análise. Nas relações comparativas entre as demais variantes, esse nível de significância é intensificado, mais ainda, entre a alta e média baixa da fala feminina [u] x [O], que possuem alto grau de diferença fonética entre si.

\subsection{Estratificação por faixa etária}

Para melhor compreendermos o comportamento acústico das vogais em variação analisadas aqui, consideramos os resultados dispostos em conjunto nas três faixas etárias controladas neste trabalho (primeira faixa etária - 15 a 25 anos, segunda faixa etária - 26 a 45 anos e terceira faixa etária - 46 em diante), pois desejamos comparar o grau de variação entre essas vogais de acordo com a faixa etária. O gráfico 03 nos remete aos valores de $\mathrm{F} 1$ e F2 em Hz, referentes a tais faixas etárias. 
Gráfico 03: Espaço acústico das variantes das vogais médias pretônicas do sexo feminino, considerando as médias dos valores em $\mathrm{Hz}$ de F1 e F2 dos dados de Cametá, zona rural, distribuídos nas três faixas etárias: 15 a 25 anos, 26 a 45 anos e 46 anos em diante.

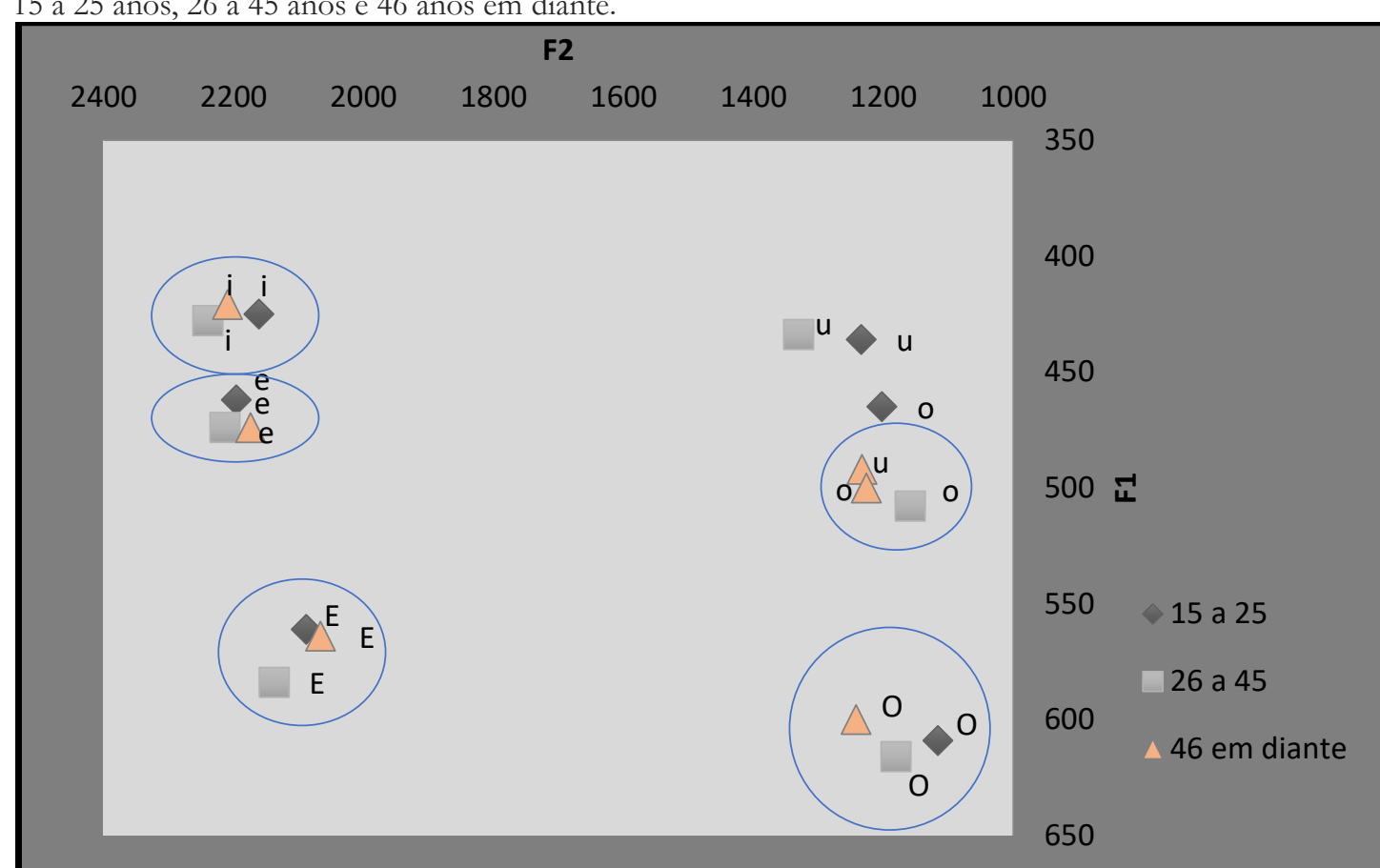

Fonte: Elaboração própria

A partir do espaço acústico da fala feminina, ficou evidenciado que as vogais médias da série anterior, nas três faixas etárias, encontram-se bem próximas entre si, compartilhando espaço acústico bastante aproximado, pois as medidas de F1 e F2, não são muito diferentes. Mas, em se tratando de série posterior, as diferenças nas três faixas etárias, alargam-se mais um pouco, uma vez que se olharmos para as variantes /o/ e [u], observaremos que as medidas acústicas de tais vogais são mais distantes. Resultado parecido foi o verificado entre a segunda (26 a 45 anos) e terceira faixa etária (46 anos em diante) para a média alta /o/, pois estão próximas acusticamente em $\mathrm{F} 1$, mas como uma ligeira tendência de /o/ da segunda faixa etária ao processo de posteriorização (F2).

$\mathrm{Na}$ terceira faixa etária, observamos também que as medidas de $\mathrm{F} 1$ para a variante /o/ e [u] são muito próximas entre si, compartilhando quase o mesmo espaço acústico, o que atesta que nesta fase há maior probabilidade de variação entre tais vogais, do que nas demais faixas etárias. Sendo que o menor grau de variação na série posterior é constatado na segunda faixa etária (26 a 45 anos) entre /o/ e [u]. Parece que os falantes adultos diferenciam nitidamente, a nível fonético, as vogais da série posterior, sem ocasionar variação significativa. Outro aspecto importante averiguado foi o fato de as vogais baixas, tanto anteriores quanto posteriores, encontrarem-se bem afastadas das demais variantes, na fala feminina.

Quando voltamos o olhar para os dados de fala masculina, verificamos que a variação entre as vogais posteriores /o/ e [u] encontra-se mais saliente na segunda faixa etária (entre 26 a 45 anos), já que estão muito próximas entre si no quadro acústico, o que as tornam mais semelhantes foneticamente. Da mesma forma que a média alta /o/ da primeira (15 a 25 anos) e da terceira faixa etária (26 a 45 anos) compartilham o mesmo espaço de aproximação fonética.

Dado interessante é o comportamento da variante $[\mathrm{u}]$, na primeira faixa etária, que apresenta maior distanciamento das vogais de sua série, fluindo em direção ao processo de centralização, o que indica que a primeira faixa etária, no que se refere a $[\mathrm{u}] \mathrm{e} / \mathrm{o} /$ não apresenta características de variação entre a altura e movimentação horizontal na cavidade bucal, em relação aos outros fonemas vocálicos. Interessante ressaltar as medidas de /o/ da terceira faixa etária e [0] da primeira faixa etária, que embora sejam vogais com traços fonéticos de formação distintas entre si, manifes- 
tam traços em variação muito próximos entre si, como pode ser visualizado no gráfico 04:

Gráfico 04: Espaço acústico das variantes das vogais médias pretônicas do sexo masculino, considerando as médias dos valores em Hz de F1 e F2 dos dados de Cametá, zona rural, distribuídos nas três faixas etárias: 15 a 25 anos, 26 a 45 anos e 46 anos em diante.

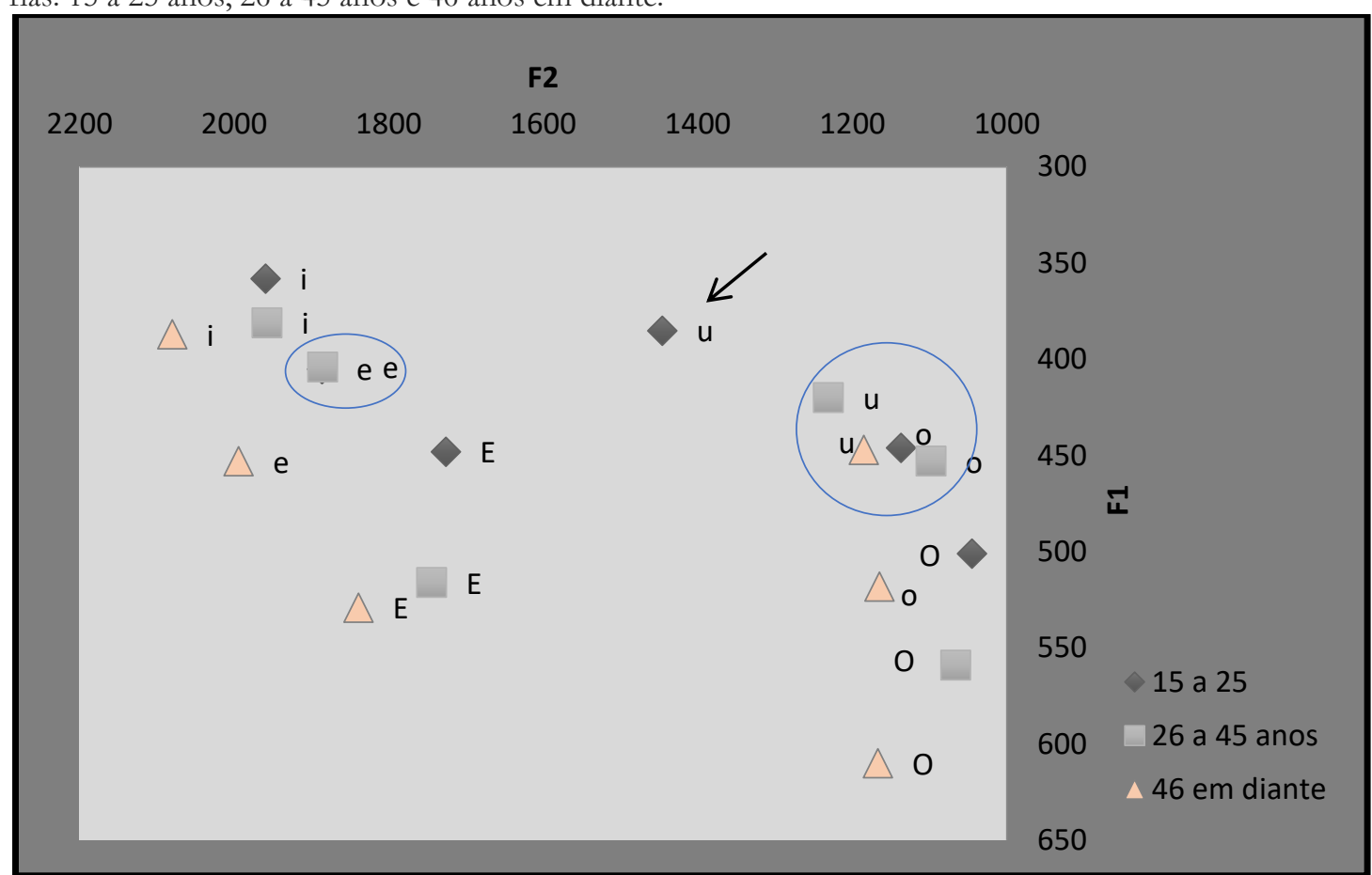

Fonte: Própria das autoras

Para a série anterior, não há muita nitidez na variação entre as vogais já que, encontram-se mais distantes acusticamente, com exceção da vogal /e/ da primeira e segunda faixas etárias, que ocupam o mesmo espaço acústico no quadro fonético das vogais faladas na zona rural de Cametá. Com relação à posterior [0] nas três faixas etárias, notamos certo distanciamento entre elas, sendo que para a segunda e terceira faixa etária, tais vogais estão mais próximas entre si e mais distantes da primeira faixa etária e mais uma vez fica claro, estudando a fala masculina, que há menor distanciamento fonético entre os espaços de contrastes, da vogal /o/ e a [u], pois as medidas de F1 $(\mathrm{Hz})$ são mais aglutinadas à altura umas das outras, o que vem mais uma vez reforçar a alta tendência que os cametaenses possuem em alternar tais vogais posteriores.

O teste-T estatístico realizado entre as vogais de mesma natureza articulatória, como [i] versus [i], mas entre as diferentes faixas etárias, demonstrou distinção de realização acústica bastante significativa na comparação entre as vogais expostas na tabela 03 , na medida em que o resultado do teste- $\mathrm{T}$ foi inferior a 0,05 .

Tabela 03: Quadro com o resultado do teste-T aplicado às médias de mesma natureza articulatória nas amostras de fala dos participantes-colaboradores estratificados nas três faixas etárias (jovem, adulto e velho) referentes ao protocolo de teste de imagens.

\begin{tabular}{|c|c|c|c|c|}
\hline \multicolumn{5}{|c|}{ TESTE - T FEMININO } \\
\hline $\begin{array}{c}\text { [i] x [i] } \\
\text { J-A }\end{array}$ & $\begin{array}{c}\mathrm{e} / \mathrm{x} / \mathrm{e} / \\
\mathrm{J}-\mathrm{A}\end{array}$ & $\begin{array}{c}\text { /e/ x /e/ } \\
\mathrm{J}-\mathrm{V}\end{array}$ & $\begin{array}{c}/ \mathrm{e} / \mathrm{x} / \mathrm{e} / \\
\mathrm{A}-\mathrm{V}\end{array}$ & $\begin{array}{c}{[\varepsilon] \times[\varepsilon]} \\
A-V\end{array}$ \\
\hline 0,00009 & 0,00021 & 0,000006 & 0,0378 & 0,005 \\
\hline $\begin{array}{c}{[\mathrm{u}] \times[\mathrm{u}]} \\
\mathrm{J}-\mathrm{A}\end{array}$ & $\begin{array}{c}\text { /o/ x /o } / \\
\text { J-A }\end{array}$ & $\begin{array}{c}\text { /o/ } \times / o / \\
\mathrm{J}-\mathrm{A}\end{array}$ & $\begin{array}{c}/ \mathrm{o} / \mathrm{x} / \mathrm{o} / \\
\mathrm{A}-\mathrm{V}\end{array}$ & $\begin{array}{c}{[\boldsymbol{P}] \times[\mathbf{P}]} \\
\mathrm{A}-\mathrm{V}\end{array}$ \\
\hline 0,000001 & 0,0001 & 0,0005 & 0,008 & 0,000006 \\
\hline \multicolumn{5}{|c|}{ TESTE - T MASCULINO } \\
\hline $\begin{array}{c}\mathrm{e} / \mathrm{x} / \mathrm{e} / \\
\mathrm{J}-\mathrm{A}\end{array}$ & $\begin{array}{c}\text { /e/ x /e/ } \\
\mathrm{J}-\mathrm{V}\end{array}$ & $\begin{array}{c}{[\varepsilon] \times[\varepsilon]} \\
\text { J-A }\end{array}$ & $\begin{array}{c}{[\mathcal{E}] \times[\mathcal{E}]} \\
\mathrm{J}-\mathrm{V}\end{array}$ & $\begin{array}{c}{[\varepsilon] \times[\varepsilon]} \\
A-V\end{array}$ \\
\hline
\end{tabular}




\begin{tabular}{|c|c|c|c|c|}
\hline 0,001 & 0,012 & 0,000002 & 0,0000009 & 0,0003 \\
\hline$[\mathbf{u}] \mathbf{x}[\mathbf{u}]$ & $/ \mathbf{o} / \mathbf{x} / \mathbf{o} /$ & $/ \mathbf{o} / \mathbf{x} / \mathbf{o} /$ & {$[\mathbf{J}] \mathbf{x}[\mathbf{J}]$} & {$[\mathbf{J}] \mathbf{x}[\mathbf{J}]$} \\
$\mathbf{A}-\mathbf{V}$ & $\mathbf{J}-\mathbf{A}$ & $\mathbf{J}-\mathbf{A}$ & $\mathbf{J - A}$ & $\mathbf{J}-\mathbf{V}$ \\
\hline 0,0128 & 0,0005 & 0,000006 & 0,0154 & 0,00038 \\
\hline
\end{tabular}

Fonte: própria das autoras

No que diz respeito à série anterior feminina, ficou evidenciado um valor distintivo entre as vogais [i] - [i] (jovem e adulto) e /e/ - /e/ (jovem - velho ${ }^{9}$. Enquanto que para o masculino, esta diferença recaí, principalmente, sobre as vogais médias baixas $[\varepsilon] /[\varepsilon]$ (jovens - adultos, jovens velhos. Para a série posterior, a diferença significativa encontra-se na alta [u] (jovem - adulto) e [0] (adulto e velho) para a fala feminina, e na fala masculina encontra-se na vogal /o/ (jovem - adulto). Tais resultados demonstram que apesar destas vogais, nas três faixas etárias, estarem em co-variação na língua falada, mesmo assim constituem categorias de realizações diferentes de variantes das medias, portanto a faixa etária do falante exerce um papel diferenciador, pois as mesmas vogais são significativamente distintas entre uma faixa etária e outra.

O teste-T estatístico realizado entre as vogais de natureza articulatória diferentes, em relação, por exemplo, à comparação entre a série posterior alta derivada /u/ e a posterior média subjacente /o/, constatamos que, de fato esta representa uma categoria diferente daquela pelo nível de significância obtido, inferior a 0,05 .

Tabela 04: Quadro com o resultado do teste-T aplicado nas médias de natureza articulatória diferentes das amostras de fala dos participantes-colaboradores estratificados em cada faixa etária (jovem, adulto e velho) referentes ao protocolo de teste de imagens.

\begin{tabular}{|c|c|c|c|c|c|}
\hline \multicolumn{3}{|c|}{ TESTE - T Feminino } & \multicolumn{3}{|c|}{ TESTE - T Masculino } \\
\hline $\begin{array}{c}\mathrm{i}] \mathrm{x} / \mathrm{e} / \\
\text { Jovem } \\
\text { Jovem }\end{array}$ & $\begin{array}{c}\text { [i] x /e/ } \\
\text { Adulto } \\
\text { Adulto }\end{array}$ & $\begin{array}{c}\text { [i] } x / e / \\
\text { Velho } \\
\text { Velho }\end{array}$ & $\begin{array}{c}\text { [i] x /e/ } \\
\text { Jovem } \\
\text { Jovem }\end{array}$ & $\begin{array}{c}{[\mathrm{i}] \mathrm{x} / \mathrm{e} /} \\
\text { Adulto } \\
\text { Adulto }\end{array}$ & $\begin{array}{c}\text { [i] x /e/ } \\
\text { Velho } \\
\text { Velho }\end{array}$ \\
\hline 0,0125 & 0,0129 & 0,00025 & 0,0125 & 0,0026 & 0,0023 \\
\hline $\begin{array}{c}\mathrm{u}] \mathrm{x} / \mathrm{o} / \\
\text { Jovem } \\
\text { Jovem }\end{array}$ & $\begin{array}{c}\mathrm{u}] \times / \mathrm{o} / \\
\text { Adulto } \\
\text { Adulto }\end{array}$ & $\begin{array}{c}\text { [u] x /o/ } \\
\text { Velho } \\
\text { Velho }\end{array}$ & $\begin{array}{c}\mathrm{u}] \mathrm{x} / \mathrm{o} / \\
\text { Jovem } \\
\text { Jovem }\end{array}$ & $\begin{array}{c}\mathrm{u}] \times / \mathrm{o} / \\
\text { Adulto } \\
\text { Adulto }\end{array}$ & $\begin{array}{c}\mathrm{u}] \mathrm{x} / \mathrm{o} / \\
\text { Velho } \\
\text { Velho }\end{array}$ \\
\hline 0,1333 & 0,000004 & 0,000000006 & 0,1333 & 0,0000002 & 0,0002 \\
\hline
\end{tabular}

Fonte: Elaboração própria

Em relação à comparação entre a série posterior alta derivada / $\mathrm{u} / \mathrm{e}$ a posterior média subjacente /o/, nas diferentes faixas etárias, notamos que, de fato, a subjacente /o/ representa uma categoria diferente da variante média, pelo nível de significância obtido, inferior a 0,05 , isto é, de 0,000000006 para velho-velho e 0,0000002, adulto-adulto. Quando se olha para cada faixa etária 15 a 25 anos (jovem), 26 a 45 anos (adulto) e 46 anos em diante (velho), observa-se que há distância fonética bem definida entre as variantes tanto da série anterior quanto da posterior no que referese aos traços físicos da vogal subjacente /e/ e da derivada [i] em variação e de /o/ e [u].

\section{Algumas Considerações obtidas}

Este estudo teve como principal objetivo caracterizar acusticamente as vogais médias pretônicas /e/ e /o/ faladas na zona rural do município da cidade de Cametá, nordeste do Estado do Pará. A coleta de dados foi realizada por meio de um teste de imagem, contendo 72 vocábulos e a partir deste, obtivemos um total de 455 ocorrências de vogais médias anteriores e 473 vogais posteriores na fala de 18 informantes naturais da cidade em análise, estratificados em sexo e faixa etária.

90 termo velho representa uma categoria, não temos a intenção de considerar pejorativamente. 
Identificamos quatro variantes: apagamento 'cab/Ǿ/ceando', 'h/Ǿ/spital'; abaixamento 'b/o/nita', 's/ $/$ /tenta'; manutenção ' $\mathrm{f} / \mathrm{e} / \mathrm{chada}$ ', ' $\mathrm{g} / \mathrm{o} / \mathrm{rdura}$ ' e alteamento 'pr/i/guiça', 'p/u/lícia', mas os falantes da zona rural do município de Cametá apresentam como variante de maior predominância as vogais médias fechadas (/e/ - 266 ocorrências e para a /o/ - 265 ocorrências), não aplicando portanto, o que tínhamos como hipótese inicial, o alteamento como maior probabilidade no português falado no lócus da pesquisa, apresentando para a derivada alta ([i] - 77 ocorrências e para a [u] - 72 ocorrências). Enquanto que a derivada baixa $([\varepsilon]-112$ ocorrências e para a $[0]-136$ ocorrências), portanto apresentaram-se maiores do que as derivadas altas.

Estudos anteriores como de Rodrigues e Araújo (2007) reforçam os nossos resultados, pois apontaram também que as vogais médias /e/ e /o/ em posição pretônica tendem à manutenção.

$\mathrm{Na}$ série anterior e posterior para as médias abertas $[\varepsilon]$ e $[\mathrm{\rho}]$ respectivamente, vimos que a posterior apresenta-se ligeiramente mais baixa que a anterior correspondente, o que em estudo posterior poderia ser revisto e comparado com a posição acústica da vogal baixa [a] em posição pretônica e com as vogais subjacentes $[\varepsilon]$ e $[0]$ em posição tônica.

A vogal alta $[\mathrm{u}]$ derivada, como em c $[\mathrm{u}] \mathrm{ruja}-/ \mathrm{o} />[\mathrm{u}]$, na fala masculina apresentou valor mais alto do que a fala feminina, fato este que nos leva, posteriormente, querer investigar se este $[\mathrm{u}]$ derivado equivale ou se aproxima de um $[\mathrm{u}]$ subjacente, como em $\mathrm{m}[\mathrm{u}] \mathrm{lher}$, com valores formânticos próximos a este último; e se há distinção significativa entre as vogais altas resultantes de variação [i] e [u] em posiç̧ão pretonica e as vogais subjacentes correspondentes em posição tônica /i/ e /u/.

Por fim, a análise acústica ratifica as análises quantitativas da variedade linguística falada em Cametá para as vogais médias em posição pretônica, apresentando como variante de maior nível de significância a manutenção das vogais médias /e/ e /o/. Isso pode ser notado na tabela 01, em que para a média anterior /e/ temos 51 ocorrências (fala masculina) e 55 (fala feminina) e para a média posterior /o/ 61 ocorrências (fala masculina) e 60 (fala feminina). Em oposição a variante de menor ocorrência de alteamento, que para a média anterior alteada /e/ > [i], 09 ocorrências (fala masculina) e 14 (fala feminina) e para a média posterior alteada /o/ > [u] 02 (masculina) e 12 (feminina).

No teste-T pudemos verificar que as vogais analisadas, principalmente a subjacente /o/ e a derivada $[\mathrm{u}]$ são estatísticamente distintas, tanto da fala masculina quanto da feminina, com 0,003 de nível de significância obtido inferior a 0,05.

Nas diferentes faixas etárias, pudemos evidenciar também pela comparação entre a posterior [u] e a média subjacente /o/, que esta pretônica posterior representa uma categoria diferente da vogal alta, pelo nível de significância obtido de 0,0000002 entre os falantes adultos e 0,000000006 para $[\mathrm{u}] \mathrm{x} / \mathrm{o} /$ para os mais velhos; ou seja, inferior a 0,05 .

\section{REFERÊNCIAS}

CAMPOS, Benedita Maria do Socorro Pinto. Alteamento vocálico em posição pretônica no português falado no município de Mocajuba-Pará. Dissertação de Mestrado (Mestrado em Letras). Universidade Federal do Pará (UFPA). Belém, 2008.

COSTA, Raquel Maria da Silva. Descrição sociolinguística das vogais médias postônicas nãofinais /o/ e /e/ no português falado no município de Cametá-PA. Dissertação de Mestrado (Mestrado em Letras). Universidade Federal do Pará (UFPA). Belém, 2010.

CRUZ, Regina; COSTA, Mara; SILVA; Ana Carolina. Análise qualitativa e acústica das vogais médias pretônicas no português falado na Amazônia paraense. In: CONGRESSO INTERNACIONAL DA ASSOCIAÇÃO BRASILEIRA DE LINGUÍSTICA, 2012, Natal. Resumos. Natal: ABRALIN, 2012. p.59-60.

COSTA, Mara; CRUZ, Regina. Análise acústica das vogais médias pretônicas dos dados de 
fala lida de Belém (PA). ABRALIN, 2014. Manaus (AM). Anais

CRUZ, Regina. Projeto Vogais do Português do Brasil PROBRAVO Variedades Linguística da Amazônia Paraense - Projeto Norte Vogais - Belém, Cametá e Mocajuba. (Coordenação Professora Dra. Regina Cruz, UFPA, CAPS e FULBRIGHIT), nível regional.

CRUZ, R. et al. As Vogais Médias Pretônicas no Português Falado nas Ilhas de Belém (PA). In ARAGÃO, S. (Org.). Estudos em fonética e fonologia no Brasil. João Pessoa (PB): GTFonética e Fonologia/ANPOLL, 2008.

CRUZ, Regina. Vogais médias pretônicas no português falado em Belém (PA): análise qualitativa e acústica. Anais IV Seminário internacional de fonologia. Porto Alegre, abril de 2012.

DIAS, M.; CASSIQUE, O.; CRUZ, R. O alteamento das vogais pré-tônicas no português falado na área rural do município de Breves (PA): uma abordagem variacionista. Revista Virtual de Estudos da Linguagem (REVEL). Porto Alegre (RS), n. 9, vol. 5, jul. 2007. (Disponível em: http://www.revel.inf.br/site2007/_pdf/9/artigos/).

LOPES, Marlúcia; CRUZ, Regina; Sistema vocálico do português falado em Cametá: caracterização acústica das vogais médias pretônicas. 29 ENANPOLL, 2014. Florianópolis (SC).

MORAES, Marlúcia Lopes. As vogais médias pretônicas /e/ e /o/ no português falado na zona rural do Município de Cametá: uma caracterização acústica. Cametá: UFPA/CUNTINS, 2015 (Trabalho de Conclusão de Curso).

NASSIF, Maíra Tavares. Análise Acústica das Vogais: estudo comparativo de F1 e F2 em indivíduos glossectomizados parciais e no grupo controle. Belo Horizonte, 2007. 30f

OLIVEIRA, Daniele de Abreu. A variação das vogais médias postônicas não-finais no Português falado na área urbana do município de Cametá (PA): uma abordagem variacionista. Belém, 2008. Trabalho de Conclusão de Curso.

RODRIGUES, Doriedson do S. Da zona urbana à rural/entre a tônica e a pretônica: o alteamento $/ \mathrm{o} />[\mathrm{u}]$ no português falado no município de Cametá/Ne paraense - uma abordagem variacionista. Dissertação de Mestrado (Mestrado em Letras). Universidade Federal do Pará (UFPA). Belém, 2005.

RODRIGUES, Doriedson do Socorro; ARAÚJO, Marivana dos Prazeres. As vogais médias pretônicas / e / e / o / no português falado no município de Cametá/PA - a harmonização vocálica numa abordagem variacionista. Cadernos de Pesquisa em Linguística, Variação no Português Brasileiro, Leda Bisol; Cláudia Brescancini (Orgas.), volume 3, Porto Alegre, novembro de 2007, pp. 104-126. 